\title{
Sustainable adsorption method for the remediation of malachite green dye using nutraceutical industrial fenugreek seed spent
}

\author{
Syed Noeman Taqui ${ }^{1} \cdot$ Mohan C. S. $^{2} \cdot$ Bibi Ahmadi Khatoon $^{2} \cdot$ Manzoore Elahi M. Soudagar $^{3} \cdot$ T. M. Yunus Khan ${ }^{4} \cdot$ \\ M. A. Mujtaba ${ }^{5} \cdot$ Waqar Ahmed $^{6} \cdot$ Ashraf Elfasakhany $^{7} \cdot$ Ravinder Kumar $^{8} \cdot$ Catalin I. Pruncu $^{9}$
}

Received: 4 May 2021 / Revised: 23 July 2021 / Accepted: 26 July 2021

(c) Crown 2021

\begin{abstract}
Nutraceutical industrial fenugreek seed spent (NIFGS), a relatively low-cost material abundantly available with nearly negligible toxicity for the bioremediation of malachite green $(\mathrm{MG})$ dye from aqueous media, is reported. Studies on the various parameters affecting the adsorption capacity of NIFGS were carried out to evaluate the kinetics and the equilibrium thermodynamics. All the experiments were designed at about $\mathrm{pH}$ 7. The adsorption isotherm model proposed by Langmuir fits better than the Freundlich isotherm model. Kinetic study data confirms the viability of pseudo-second-order model. Calculated thermodynamic factors suggest that the adsorption phenomenon is endothermic, almost instantaneous, and physical in nature.
\end{abstract}

Keywords Nutraceutical industrial fenugreek seed spent $\cdot$ Malachite green $\cdot$ Adsorption studies

Ravinder Kumar

rav.chauhan@yahoo.co.in

Catalin I. Pruncu

catalin.pruncu@strath.ac.uk

Syed Noeman Taqui

noemansyed89@gmail.com

Mohan C. S.

mohan0785@gmail.com

Bibi Ahmadi Khatoon

bibiahmadikhatoon@gmail.com

Manzoore Elahi M. Soudagar

me.soudagar@gmail.com

T. M. Yunus Khan

yunus.tatagar@gmail.com

M. A. Mujtaba

m.mujtaba@uet.edu.pk

Waqar Ahmed

waqarum.ah@gmail.com

Ashraf Elfasakhany

ashr12000@yahoo.com
2 Department of Chemistry, Yuvaraja's College (Autonomous), University of Mysore, Mysuru 570005, Karnataka, India

3 Department of Mechanical Engineering, School of Technology, Glocal University, Delhi-Yamunotri Marg, SH-57, Mirzapur Pole, Saharanpur District, Uttar Pradesh 247121, India

4 Department of Mechanical Engineering, College of Engineering, King Khalid University, Abha 61421, Kingdom of Saudi Arabia

5 Department of Mechanical Engineering, University of Malaya, 50603 Kuala Lumpur, Malaysia

6 Malaysia-Japan International Institute of Technology (Mjiit), UTM Kuala Lumpur, Jalan Sultan Yahya Petra, Kuala Lumpur 54100, Malaysia

7 Mechanical Engineering Department, College of Engineering, Taif University, P.O. Box 11099, Taif 21944, Saudi Arabia

8 School of Mechanical Engineering, Lovely Professional University, 144411 Phagwara, India

9 Design, Manufacturing \& Engineering Management, University of Strathclyde, Glasgow G1 1XJ, Scotland, UK

1 CSIR - Central Food Technological Research Institute, Mysore 570020, Karnataka, India 


\section{Introduction}

A report on nutraceutical industries suggests a possible turnover of USD 722.5 billion by 2027 [1]. These industries produce unprecedented myriad tons of spent/waste. The nutraceutical industrial spent (NIS) produced as a by-product has no feed, fuel, and fertilizer value [2]. Fenugreek plant (Trigonellafoenum-graecum $L$.) belongs to the legume family, and fenugreek seeds are extensively used as nutraceuticals [3]. India ranks first by producing about $2.40 \times 10^{5}$ tons of fenugreek seed which is extensively used as a nutraceutical [4]. The spent left after extracting the lead compound is generally identified as nutraceutical industrial fenugreek spent (NIFGS). The use of NIFGS as an adsorbent for eliminating anionic bisazo dye from aqueous media [5] has been reported inrecent times.

The techniques and procedures used for the remediation of dyes in textile industrial effluents (TIE) are broadly classified as biological [6, 7], biological-cum-chemical [8], chemical [9], electro-separation [10], electro-coagulation [11], physical methods using membranes $[12,13]$, use of nanomaterials and composites [14-20], food products [21], and activated carbon [22]. The high cost of plant establishment, increased operational cost, the additional cost of regeneration of the adsorbent, sensitivity to changes in the participation of the wastewater and its ingredients, and disposal of residual sludge $[23,24]$ are the major issues and serious limitations reported in the literature.

Currently, adsorption technique with the characteristics of simplicity, efficiency, minimum discharge of toxic byproducts[25-27], and possibilities of scaling up to field-level is widely employed for remediation of toxic dye and allied materials from TIE. Pore structure, cost, abundant availability, and ready-to-use adsorbent are the qualities required for the adsorption process. Most of the proposed materials as adsorbents do not qualify for the textile industry's needs and demands. Also, scant literature available on the problem of sludge generated during the process poses an additional challenge. These limitations have created a surge amongst scientists to look for an economically feasible and environmentally acceptable alternative [28-31].

Presently, NIS produced by nutraceutical industries is disposed of as landfills and as low-calorific value fuel, which is attributed to the pore structure, which traps moisture from the atmosphere. Incineration/burning of NIS results in pollution in the form of GHG emissions and leaves a carbon footprint. Utilization of NIS as an adsorbent to amputate the toxic substances from TIE ecologically alleviates waste disposal problems and addresses sustainability needs and demands.

In the present investigation, we report the use of NIFGS for the remediation of cationic malachite green (MG) as a potential adsorbent belonging to triarylmethane class of dyesfrom water and TIE. The possibilities of the use of the resultant dye-adsorbed clay minerals commonly known as "sludge" as filler/reinforcement material in the fabrication of the composites will address the problems encountered by the polymer industry.

\section{Experimental}

\subsection{Studies on the variables affecting adsorption of MG dye on NIFGS}

The influence of experimental parameters ( $\mathrm{pH}$, initial MG dye concentration,adsorbent dose, and temperature) was analyzed using batch experiments. For preparing stock sol. of MG $\left(1000 \mathrm{mg} \mathrm{L}^{-1}\right)$, double-distilled water was used. A required solution concentration $\left(25-200 \mathrm{mg} \mathrm{L}^{-1}\right)$ was obtained from the stock solution. A series of 250$\mathrm{mL}$ Erlenmeyer flask and 50-mL aqueous MG dye solution $\left(25-200 \mathrm{mg} \mathrm{L}^{-1}\right)$ were added. A required amount of NIFGS was introduced into each flask. Evaluations were conducted based on the effects of varying parameters such as $\mathrm{pH}(2,4,6,7,8,10$, and 12), MG dye initial concentration (25-200 mg L $\left.{ }^{-1}\right)$, and dosage of adsorbent $(0.025-0.200 \mathrm{~g}$ $\left.50 \mathrm{ml}^{-1} ; 0.500-4.000 \mathrm{~g} \mathrm{~L}^{-1}\right)$. Three temperatures $(303,313$, and $323 \mathrm{~K}$ )were selected with an initial dye concentration of $200 \mathrm{mg} \mathrm{L}^{-1}$ to study the influence of temperature on the process of adsorption. The solution was subjected to stirring on a thermostatic orbital shaker at $165 \mathrm{rpm}$ for $180 \mathrm{~min}$. The samples were withdrawn at a predetermined equilibrium time. The unadsorbed MG dye in the solution phase was removed from NIFGS by centrifugation at $3000 \mathrm{rpm}$ for $5 \mathrm{~min}$. If the solution was unclear, the centrifugation was repeated for an additional $5 \mathrm{~min}$. The MG dye concentration at equilibrium about the supernatant centrifuged solution was found out utilizing the Perkin-Elmer Lambda EZ-201 UV-vis spectra at $\lambda_{\max } 590 \mathrm{~nm}$. To examine the influence in a range of $\mathrm{pH} 2-12$, batch experiments were performed.The $\mathrm{pH}$ of the solution was attuned utilizing $0.01-1.00 \mathrm{MHCl}$ or $\mathrm{NaOH}$ solution. Adsorption kinetic studies of MG dye solution $\left(200 \mathrm{mg} \mathrm{L}^{-1}\right)$ and three temperatures $(303,313$, and $323 \mathrm{~K}$ ) were selected to carry out experiments with time as an independent variable. The data were fitted into Eqs. 1, 2, and 3-Table 1. Experiments were replicated thrice, and the mean values were considered. 
Table 1 Mathematical equations used in the investigation [32]

\begin{tabular}{|c|c|c|c|}
\hline Eq. no & Equation & Description & Parameter \\
\hline \multicolumn{4}{|c|}{ General adsorption studies } \\
\hline 1 & $q_{e}=\frac{\left(C_{o}-C_{e}\right) V}{W}$ & Adsorption capacity at equilibrium & \multirow{3}{*}{$\begin{array}{l}q_{e} \text { is adsorption capacity at equilibrium }\left(\mathrm{mg} \mathrm{L}^{-1}\right) \\
q t \text { is adsorption capacity at time } t\left(\mathrm{mg} \mathrm{L}^{-1}\right) \\
C_{o} \text { is initial adsorbent concentation }\left(\mathrm{mg} \mathrm{L}^{-1}\right) \\
C e \text { is adsorbent concentation at equilibrium }(\mathrm{mg} \mathrm{L}-1) \\
C_{t} \text { is adsorbent concentation at time } t \\
V \text { is the volume of the absorbate solution }(\mathrm{L}) \\
W \text { is the weight of the adsorbent }(\mathrm{g})\end{array}$} \\
\hline 2 & $q_{t}=\frac{\left(C_{o}-C_{t}\right) V}{W}$ & Adsorption capacity at time $t$ & \\
\hline 3 & $R E \%=\left[\frac{C_{o}-C_{e}}{C_{o}}\right] * 100$ & Percentage removal efficiency $(R E)$ & \\
\hline \multicolumn{4}{|c|}{ Adsorption isotherm studies } \\
\hline 4 & $q_{e}=\frac{Q_{m} K_{a} C_{e}}{1+K_{a} C_{e}}$ & Langmuir isotherm & $\begin{array}{l}Q_{m} \text { is the monolayer adsorption capacity }\left(\mathrm{mg} \mathrm{g}^{-1}\right) \\
K a \text { is Langmuir isotherm adsorption constant }\left(\mathrm{L} \mathrm{mg}^{-1}\right)\end{array}$ \\
\hline 5 & $R_{L}=\frac{1}{1+K_{a} C_{0}}$ & $\begin{array}{l}\text { Separation factor of } \\
\text { Langmuir isotherm }\end{array}$ & $\begin{array}{l}R_{L} \text { factor implies whether the adsorption unfavourable } \\
\text { when }\left(R_{L}>1\right) \text {, linear }\left(\mathrm{R}_{L}=1\right) \text {, favourable }\left(0<\mathrm{R}_{L}<1\right) \\
\text { and irreversible }\left(\mathrm{R}_{L}=0\right)\end{array}$ \\
\hline 6 & $q_{e}=K_{F} C_{e}^{1 / n_{F}}$ & Freundlich isotherm & $\begin{array}{l}K_{F} \text { is Freudlich isotherm adsorption capacity constant } \\
\left(\mathrm{mg} \mathrm{g}^{-1}\right) \\
n_{F} \text { is heterogeneity factor indicates the nature of } \\
\text { adsorption is chemisorption }\left(n_{F}<1\right) \text {, linear }\left(n_{F}=1\right) \\
\text { or physisorption }\left(n_{F}=1\right)\end{array}$ \\
\hline \multicolumn{4}{|c|}{ Adsorption kinetic studies } \\
\hline 7 & $q_{t}=q_{e}\left(1-e^{-k_{1} t}\right)$ & Pseudo-first-order equation & $k_{l}$ is pseudo-first order rate constant $\left(\mathrm{s}^{-1}\right)$ \\
\hline 8 & $q_{t}=\frac{q_{e}^{2} k_{2} t}{1+q_{e} k_{2} t}$ & Pseudo-second-order equation & $\begin{array}{l}k_{2} \text { is pseudo-second-order rate constant }\left(\mathrm{mol}^{-1} \mathrm{~L}^{-1} \mathrm{~s}^{-1}\right) \\
\text { " } t \text { " is time of adsorption }(\mathrm{s})\end{array}$ \\
\hline \multicolumn{4}{|c|}{ Adsorption thermodynamic studies } \\
\hline 9 & $\Delta G^{0}=\Delta H^{0}-\Delta S^{0} T$ & Standard Gibbs free energy & \multirow{4}{*}{$\begin{array}{l}\Delta G^{0} \text { is Standard Free Energy }\left(\mathrm{J} \mathrm{mol}^{-1}\right) \\
\Delta H^{0} \text { is Enthalpy Change }\left(\mathrm{J} \mathrm{mol}^{-1}\right) \\
\Delta S^{0} \text { is Entropy Change }\left(\mathrm{J} \mathrm{mol}^{-1} \mathrm{~K}^{-1}\right) \\
\mathrm{T} \text { is absolute temperature }(\mathrm{K}) \\
\mathrm{R} \text { is ideal gas constant }\left(\mathrm{J} \mathrm{mol}^{-1} \mathrm{~K}^{-1}\right) \\
K_{e q} \text { is chemical equilibrium constant } \\
C_{o} \text { is initial adsorbent concentration }\left(\mathrm{mg} \mathrm{L}^{-1}\right) \\
C_{e} \text { is adsorbent concentration at equilibrium }\left(\mathrm{mg} \mathrm{L}^{-1}\right)\end{array}$} \\
\hline 10 & $\Delta G^{\circ}=-R T \ln K_{e q}$ & $\begin{array}{l}\text { Standard Gibbs free energy at chemical } \\
\text { equilibrium }\end{array}$ & \\
\hline 11 & $K_{e q}=\frac{C_{o}}{C_{e}}$ & Thermodynamic equilibrium constant & \\
\hline 12 & $\ln K_{e q}=\frac{\Delta S^{\circ}}{R}-\frac{\Delta H^{\circ}}{R}$ & $\begin{array}{l}\text { Variant of standard Gibbs } \\
\text { free energy }\end{array}$ & \\
\hline
\end{tabular}

\section{Results and discussion}

\subsection{Surface characterization}

The surface characterization was conducted through SEM. It was found that the NIFGS surface texture has a porous and fibrous structure which enhances the adsorption of the substrate (dye) on it. Figure 1a shows SEM image of NIFGS, and Fig. 1b shows SEM image of MG adsorbed on NIFGS.

IR spectra of NIFGS (Fig. 2a) provides the information pertaining to the functional groups present. A stretch of $\mathrm{C}-\mathrm{H}$ bond in the saturated carbon results in the band at $2926 \mathrm{~cm}^{-1}$. The phenomenon of $\mathrm{C}=\mathrm{C}$ stretching results in the bands depicted at $1627 \mathrm{~cm}^{-1}, 1638 \mathrm{~cm}^{-1}$, and $1652 \mathrm{~cm}^{-1}$. Vibrations at $\mathrm{C}-\mathrm{O}$ bonds and a bend at $\mathrm{O}-\mathrm{H}$ bond result in the band seen at $1374 \mathrm{~cm}^{-1}$ and $1325 \mathrm{~cm}^{-1}$, and $1246 \mathrm{~cm}^{-1}$ and $1160 \mathrm{~cm}^{-1}$, respectively. The bands at $1103 \mathrm{~cm}^{-1}$ and $1031 \mathrm{~cm}^{-1}$ are attributed to $\mathrm{C}-\mathrm{O}-\mathrm{H}$ and $\mathrm{C}-\mathrm{O}-\mathrm{C}$ bond stretching, respectively.
As seen in Fig. 2c, a clear distinction is witnessed in the spectrum of MG adsorbed onto NIFGS compared to the standalone spectrum of MG (Fig. 2b). This conclusively indicates the dye being adsorbed onto the Fenugreek spent. The bands observed between 3300 and $3600 \mathrm{~cm}^{-1}$ are due to the two phenolic groups' presence, namely hydroxyl (-OH) and carboxylic acid $(-\mathrm{COOH})$, and these two groups are responsible for the interaction with the dye. Therefore, the carboxylate anion being axially deformed in an asymmetric manner results in the band between 1550 and $1650 \mathrm{~cm}^{-1}$ and asymmetrical deformation results in the weaker band at $1400 \mathrm{~cm}^{-1}$.

\subsection{Point of zero charge $\left(\mathrm{pH}_{\mathrm{z}}\right)$}

The $\mathrm{pH}_{\mathrm{z}}$, determined by preparing $0.1 \mathrm{M} \mathrm{KCl}$, adjusts the initial $\mathrm{pH}$ between 2.0 and 12.0 with $\mathrm{HCl}$ and $\mathrm{NaOH}$, respectively. Fifty milliliters of $0.1 \mathrm{M} \mathrm{KCl}$ with pre-set was poured in a $250-\mathrm{mL}$ conical flask and $50 \mathrm{mg}$ of NIFGS was added. After $24 \mathrm{~h}$, the change in the $\mathrm{pH}$ of the solutions was 

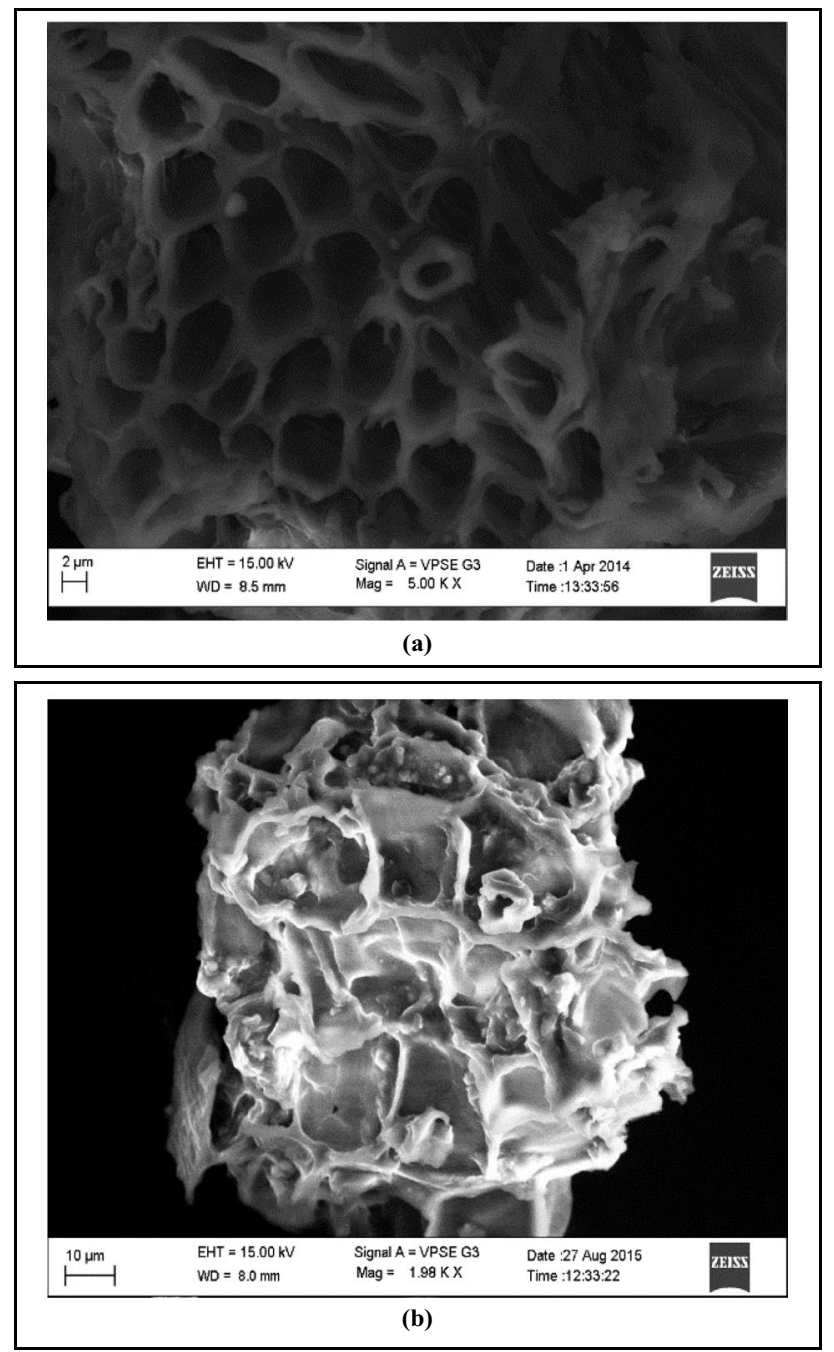

Fig. 1 a SEM image of NIFGS, b SEM image of MG-NIFGS

measured with a $\mathrm{pH}$ meter. The graphs between $\mathrm{pH}_{\text {final }}$ and $\mathrm{pH}_{\text {initial }}$ were plotted. The point of intersection of the curves at $\mathrm{pH} 7.1$ gives the $\mathrm{pH}_{\mathrm{z}}$ of NIFGS (Fig. 3).

\subsection{The influence of variables on MG adsorption on NIFGS}

\subsubsection{Solution $\mathrm{pH}$}

The adsorption capacity of NIFGS depends on pHsolution. The $\mathrm{pH}$ plays two crucial roles: first, it influences the adsorbent surface's characteristics and second, the dye solution's chemistry [33]. The $\mathrm{pH}$ as a parameter assumes importance to substantiate the efficiency of the adsorbent under study. The knowledge of this parameter is significant when the process is scaled to commercial levels [34]. There was a marginal increase in the adsorption capacity exhibited by the NIFGS as the solution $\mathrm{pH}$ increased, and when the NIFGS was subjected to acidic media, its maximum capacity of adsorption was observed. This observation is attributed to the fact that the lower $\mathrm{pH}$ refers to acidic media wherein the surplus of hydrogen ions compete for the adsorption at the targeted sites with the adsorbate's cations. As the solution $\mathrm{pH}$ increases, the surface charge per unit area lowers, wherein the repulsion of the dye's cations and the surface of NIGFS is reduced.This behavior is explained as follows: many $\mathrm{H}^{+}$ions present in the lower $\mathrm{pH}$ range compete with the dye's cation, which increases repulsion between the two charged species. Conversely, at higher $\mathrm{pH}$, the negatively charged $\mathrm{OH}^{-}$attracts the dye's cation and negatively charged species (Fig. 4a).

\subsubsection{Initial MG dye concentration}

The profound influence of initial dye concentration on the adsorption capacity of NIFGS was studied. The dye's application onto NIFGS increased from 20 to $75 \mathrm{mg} \mathrm{g}^{-1}$ with the rise in the initial dye concentration ranging $25-200 \mathrm{mg} \mathrm{L}^{-1}$. The increase in the dye concentration results in an enhanced concentration gradient. The high gradient augments the driving force to the dye solution, which helps rise in the adsorptioncapacity of NIFGS (Fig. 4b). The dye uptake by NIFGS gets enhanced with the increase in contact time. The maximum adsorption of MG from an aqueous solution was observed at 180 min of contact time. Adsorption was rapid initially due to the dye getting adsorbed onto the exterior surface. Later, the dye molecules probably enter the NIFGS pores (interior surface), which is a slow process. The adsorption of MG was more with higher concentration, and it reached almost constant after attaining equilibrium. Furthermore, it was observed that the adsorption reached almost constant after attaining equilibrium [35].

\subsubsection{Effect of adsorbent dosage}

The dosage as a parameter profoundly influences the commercialization of the process because it decides the economic viability [36]. Interestingly, the increase in adsorbent dosage from 0.500 to $4.000 \mathrm{~g} \mathrm{~L}^{-1}$ decreased MG dye quantity (Fig. 4c). This observation assumes importance in the commercialization process, which infers that the number of trials with optimum amounts of the adsorbent enhances $\mathrm{MG}$ dye removal efficiency from the aqueous solutions.

\subsection{Effect of temperature}

Keeping in view the focus to scale to commercial applications, evaluation of the process of adsorption of dyes onto NIFGS as a function of solution temperature was studied. The influence of temperature on MG dye adsorption onto NIFGS is presented in Fig. 4d. As seen in the temperature 
Fig. 2 FTIR spectra of (a) NIFGS,(b) MG dye, and (c) MG dye adsorbed onto NIFGS

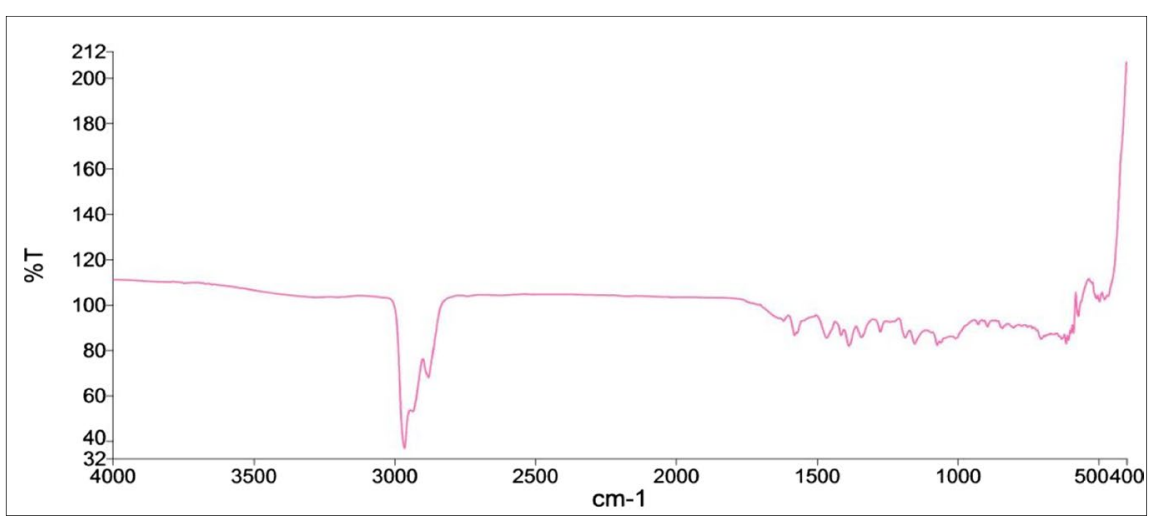

(a)

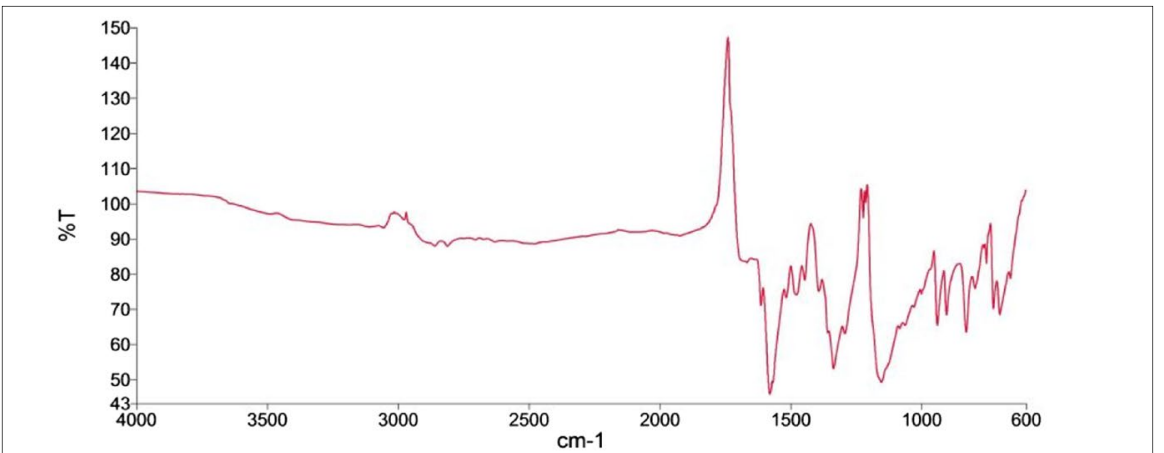

(b)

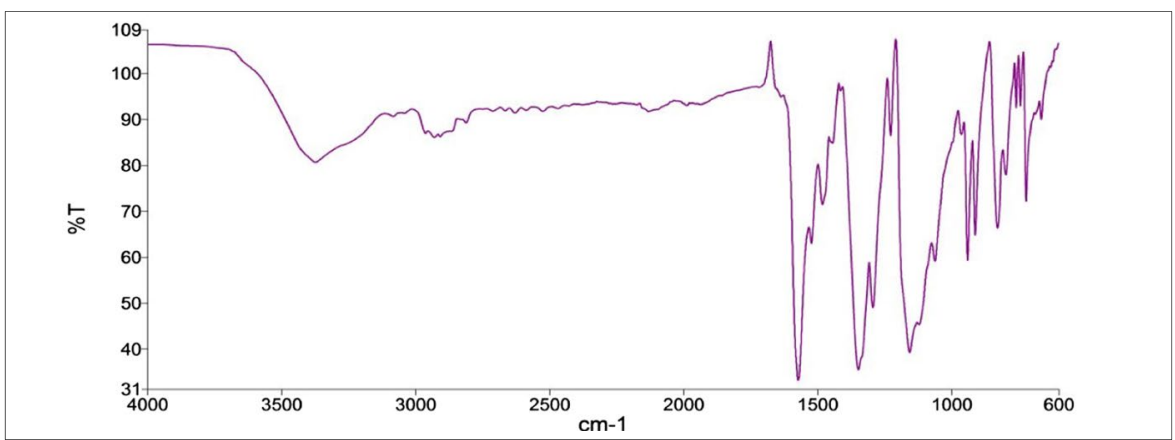

(c) profile against the adsorption capacity, an exothermic process indicates a direct correlation between the temperature and adsorption capacity. This is attributed to the dye molecules' kinetic energy by which the intra-particle diffusion of the dye molecules is high as the temperature increases. This promotes a more vital interaction between the subjected dye and the nutraceutical industrial spent acting as adsorbent. The data obtained for the classical thermodynamic parameters, namely, $\Delta \mathrm{G}^{\mathrm{o}}, \Delta \mathrm{H}^{\mathrm{o}}$, and $\Delta \mathrm{S}^{\mathrm{o}}$ indicate the nature and type of a reaction. For example, the positive $\Delta \mathrm{H}^{\circ}$ (enthalpy) values obtained from 303 to $323 \mathrm{~K}$ of NIFGS indicate an endothermic process. The overall negative values of $\Delta \mathrm{G}^{\circ}$ (free energy) obtained for the MG-NIFGS system confirm the adsorption process's spontaneity and viability. The magnitude of $\Delta G^{\circ}$ values shows the rapid and spontaneous adsorption at a lower temperature. The positive value of $\Delta S^{\circ}$ indicates that the enhanced randomness at the solid/ solution interfaces with the desired affinity of MG towards NIFGS [37]. 
Fig. 3 Point of zero charges of NIFGS [5]

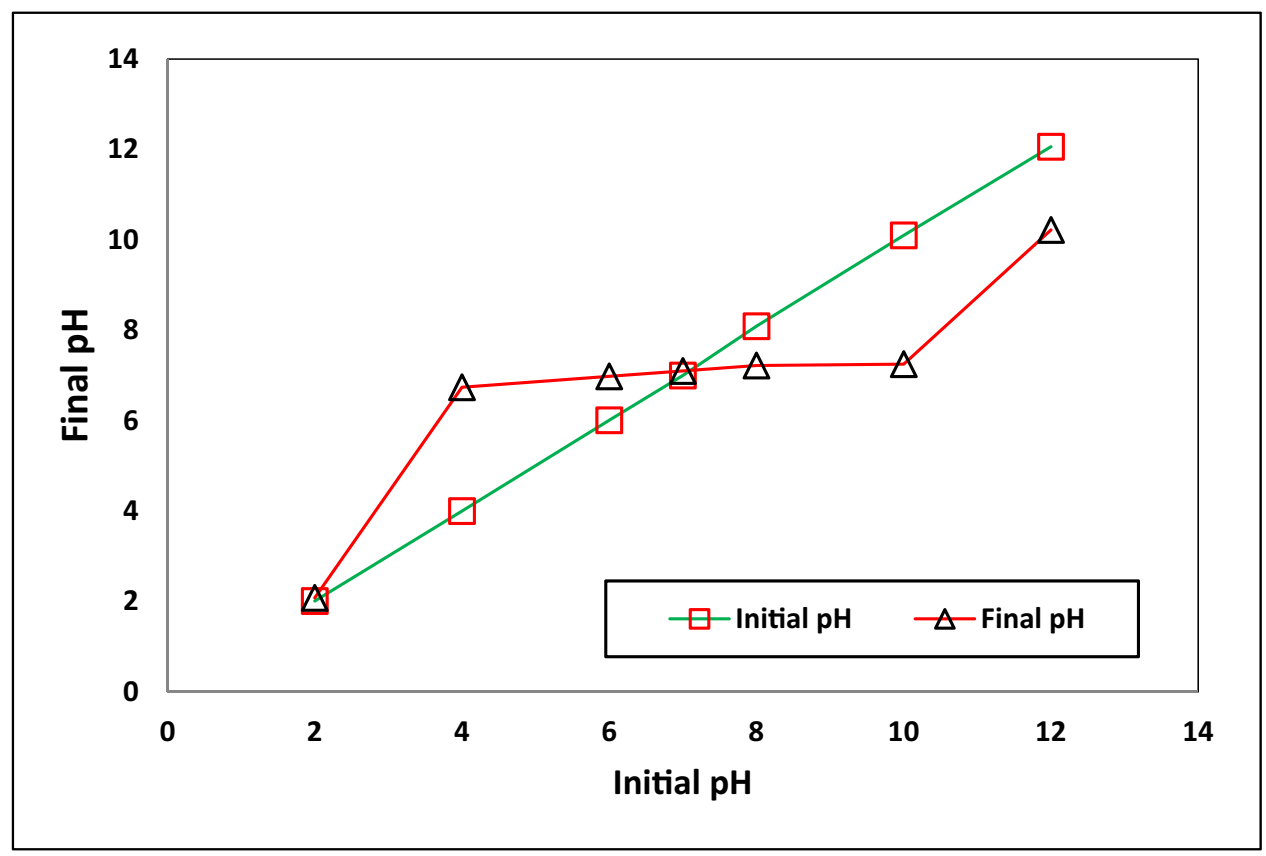

\subsection{Adsorption isotherms-modeling analysis}

The main criterion of the study of adsorption isotherms was to select a model where $q_{e}$ (the experimental equilibrium) values were almost equal to $Q_{m}$ (monolayer adsorption capacity) value with a coefficient of determination $\left(R^{2}\right)$ value $\geq 0.90$. To refine the data and distinguish between results obtained by two isotherm models, SSE and $\chi^{2}$ as two additional error functions were incorporated in our current study. Langmuir [38] proposed a model assuming that the adsorbent will have active sites possessing almost uniform energies. The equations of the Langmuir isotherm model are shown in Eqs. 4 and 5-Table 1. This was further established on the idea that no lateral interaction takes place between adsorbed molecules. A plateau in a two-dimensional graph with equilibrium concentration $\left(C_{e}\right)$ as independent variable and $q_{e}$ as dependent variable characterizes that the active sites are almost fully saturated on the adsorbent's surface, and the Langmuir isotherm curve is presented in Fig. 5a. This implies that further adsorption cannot occur, and the possibility of multilayer adsorption of the dye is ruled out. Compared to the Langmuir isotherm model, Freundlich proposed heterogeneity in the process of adsorption due to different energy of the surface sites, which likely results in multilayer adsorption and the Freundlich isotherm curve is presented in Fig. 5b. The heterogeneity factor $\left(n_{F}\right)$ indicates whether the nature of adsorption is linear $\left(n_{F}=1\right)$, chemisorption $\left(n_{F}<1\right)$, or physisorption $\left(n_{F}>1\right)$ [39]. In the present study, the value of $n_{F}$ about 1.096 indicates that the adsorption favored normal Langmuir isotherm and is physisorption. The fitting of Langmuir and Freundlich isotherms $\left(R^{2}\right)$ to the experimental is indicated by the correlation coefficient, which is 0.991 and 0.952 , respectively, where $R^{2}$ is the correlation coefficient, and the data fits well. The mathematical expression is shown in Eq. 6-Table 1. The values suggest that the dye's transfer from the bulk solution using NIFGS is physisorption and favors Langmuir isotherm.

\subsection{Adsorption kinetics}

Kinetic studies carried out using three concentrations 50, 100 , and $200 \mathrm{mg} \mathrm{L}^{-1}$ and at three temperatures at 303,313 , and $323 \mathrm{~K}$, respectively, provided variation in the adsorption rate. The results of the pseudo-first-order model [40] are computed using Eq. 7 (Table 1) and depicted in Fig. 6. Pseudo-second-order model [41] computed using Eq. 8 (Table 1) and depicted in Fig. 7 confirms that the pseudosecond-order model has best fit for the MG-NIFGS system (Table 2).

\subsection{Thermodynamics of the adsorption process}

$\Delta G^{\circ}$ and $\Delta S^{\circ}$ are Gibbs free energy and entropy change of MG dye-NIFGS system. They are the main features of the process design of adsorption thermodynamics. The values of the various thermodynamic parameters calculated are presented in Table 3. The decrease in the negative values of $\Delta G^{\circ}$ with an increase in the temperature infers that the adsorption process is almost spontaneous at lowtemperatures [42-44]. The relationship of $\Delta H^{\circ}, \Delta S^{\circ}$, and $E_{\mathrm{a}}$ is presented in Eqs. 9, 10, 11, and 12-Table 1. The positive values of 
Fig. 4 Effect of parameters on MG-NIFGS system

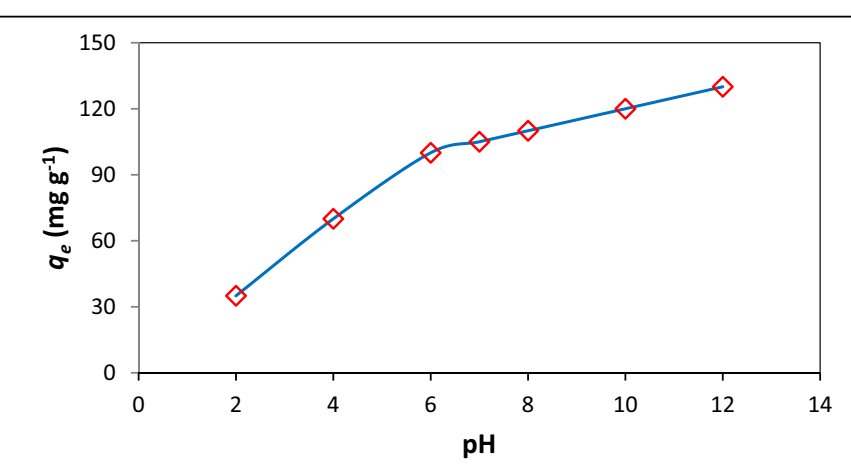

(a)

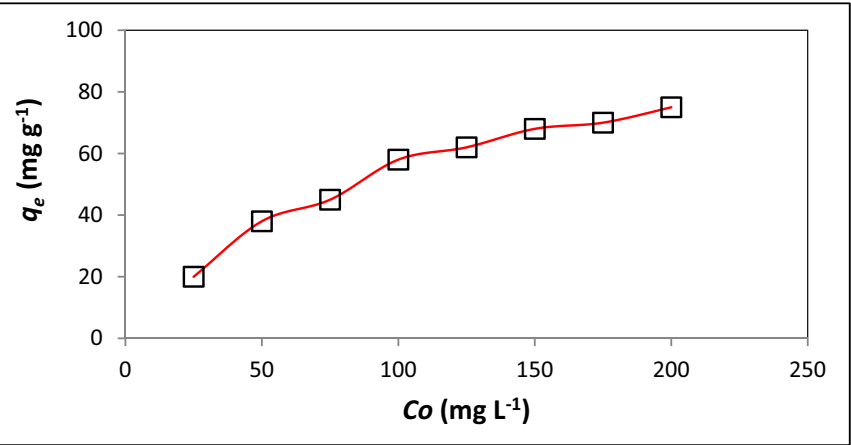

(b)

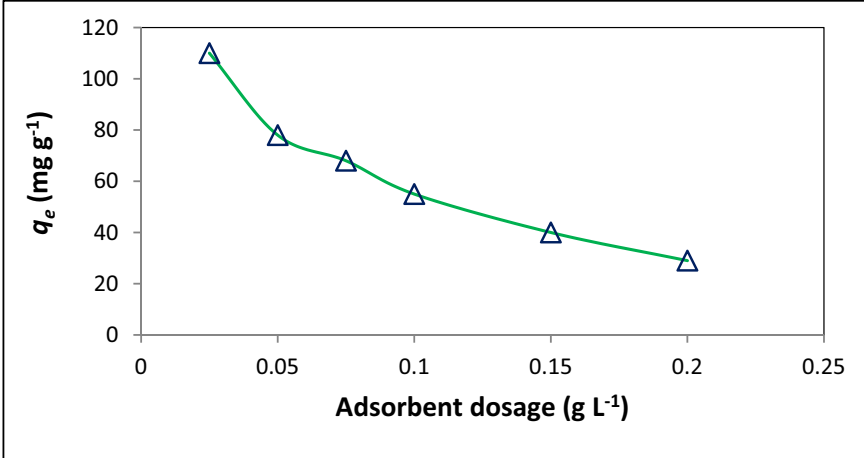

(c)

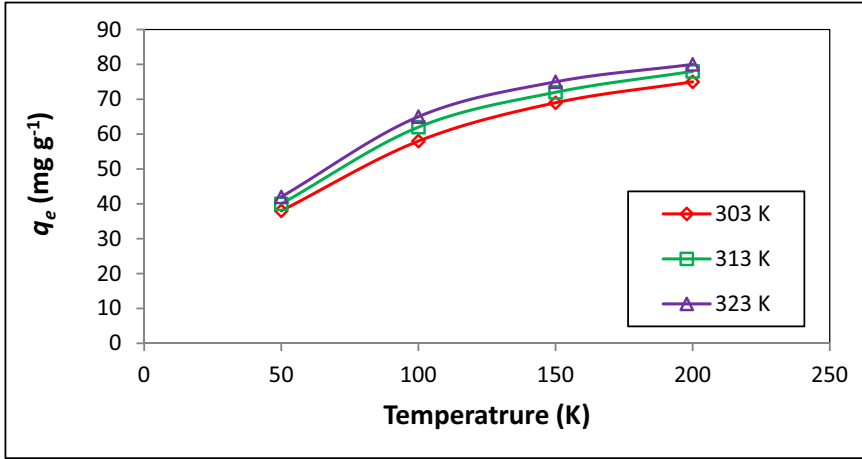

(d) 


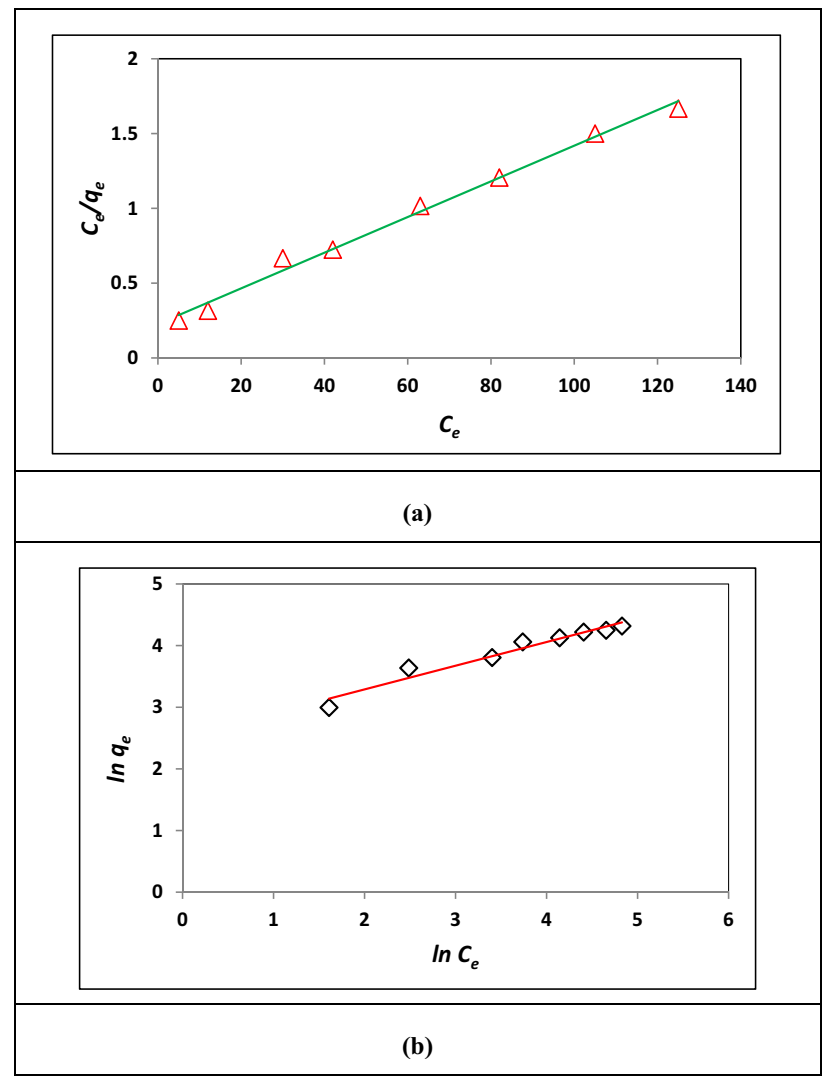

Fig. 5 Fitting of adsorption data to (a) Langmuir and (b) Freundlichadsorption isotherm MG-NIFGS system

$\Delta S^{\circ}$ indicate the decrease in the randomness at the dye/ NIFGS interface.

\section{Conclusions}

The interactions between the NIFGS as adsorbent and MG dye as adsorbate showed an experimental equilibrium $\left(q_{e}\right)$ value of $105.00 \mathrm{mg} \mathrm{g}^{-1}$ at almost neutral $\mathrm{pH}, 130 \mathrm{mg} \mathrm{g}^{-1}$ at $\mathrm{pH} \mathrm{2}$, and $168 \mathrm{mg} \mathrm{g}^{-1}$ at statistically optimized conditions. The adsorption follows the Langmuir isotherm model. The interactions between NIFGS and MG were physical in nature and followed second-order kinetics. This work has relevance to three industrial sectors, namely, textile industries, nutraceutical industries, and plastic industries. Industrial production has a linear model to create value in making the product and completes the life-cycle with the disposal after use. This model seriously affects the environment and ecology due to the unprecedented problem of resource depletion. To address the issue of resource depletion, there is a need for the industries to shift from virgin inputs to recycled and/or reuse products. This article is a step in this direction.
Acknowledgements The authors extend their appreciation to the Deanship of Scientific Research at King Khalid University, Saudi Arabia, for funding this work through Research Group Program under Grant No.: R.G.P 2/147/42. This work was supported by Taif University researchers supporting project number (TURSP-2020/40), Taif University, Taif, Saudi Arabia.

Author contribution S. N. Taqui: Formal analysis, writing-original draft, and investigation. Mohan C.S: methodology, writing, and review and editing. Manzoore Elahi M Soudagar and MA Mujtaba: writing - original draft, analysis of results, and review and editing. B. A. Khatoon, and Waqar Ahmed: formal analysis. Ravinder Kumar and Catalin I. Pruncu: review and editing. T.M. Yunus Khan and Ashraf Elfasakhany: Support, review and editing.

\section{Declarations}

Conflict of interest The authors declare no competing interests.

Open Access This article is licensed under a Creative Commons Attribution 4.0 International License, which permits use, sharing, adaptation, distribution and reproduction in any medium or format, as long as you give appropriate credit to the original author(s) and the source, provide a link to the Creative Commons licence, and indicate if changes were made. The images or other third party material in this article are included in the article's Creative Commons licence, unless indicated otherwise in a credit line to the material. If material is not included in the article's Creative Commons licence and your intended use is not permitted by statutory regulation or exceeds the permitted use, you will need to obtain permission directly from the copyright holder. To view a copy of this licence, visit http://creativecommons.org/licenses/by/4.0/.

\section{References}

1. Nutraceutical Market Size, Share \& Trends Analysis Report By Product (Dietary Supplements, Functional Foods, Functional Beverages), By Region, And Segment Forecasts, 2020-2027, Available at: https://www.grandviewresearch.com/industry-analysis/ nutraceuticals-market. Accessed 13 Dec 2020

2. Dhaif-Allah MAH, Taqui SN, Syed UT, Syed AA (2019) Development of sustainable acid blue 113 dye adsorption system using nutraceutical industrial Tribulus terrestris spent. SNApplied Sciences 1(4):330. https://doi.org/10.1007/s42452-018-0125-5

3. Wani SA, Kumar P (2018) Fenugreek: a review on its nutraceutical properties and utilization in various food products. J Saudi Soc Agric Sci 17(2):97-106

4. https://www.ceicdata.com/en/india/production-of-horticulturecrops-inindia/production-horticulture-crops-spices. Accessed 23 Nov 2020

5. Dhaif-Allah MA, Taqui SN, Syed UT, Syed AA (2020) Kinetic and isotherm modeling for acid blue 113 dye adsorption onto lowcost nutraceutical industrial fenugreek seed spent. Appl Water Sci 10(2):1-16

6. Sharma B, Dangi AK, Shukla P (2018) Contemporary enzyme based technologies for bioremediation: a review. J Environ Manage 210:10-22

7. Jebapriya GR, Gnanadoss JJ (2013) Bioremediation of textile dye using white rot fungi: a review. International Journal of Current Research and Review 5(3):1-13

8. Rai HS, Bhattacharyya MS, Singh J, Bansal TK, Vats P, Banerjee UC (2005) Removal of dyes from the effluent of textile and 
Fig. 6 Kinetics data fitted to pseudo-first order with initial MG concentration (a) $50 \mu \mathrm{g}$ $\mathrm{mL}^{-1}$, (b) $100 \mu \mathrm{g} \mathrm{mL}^{-1}$, and (c) $200 \mu \mathrm{g} \mathrm{mL}^{-1}$

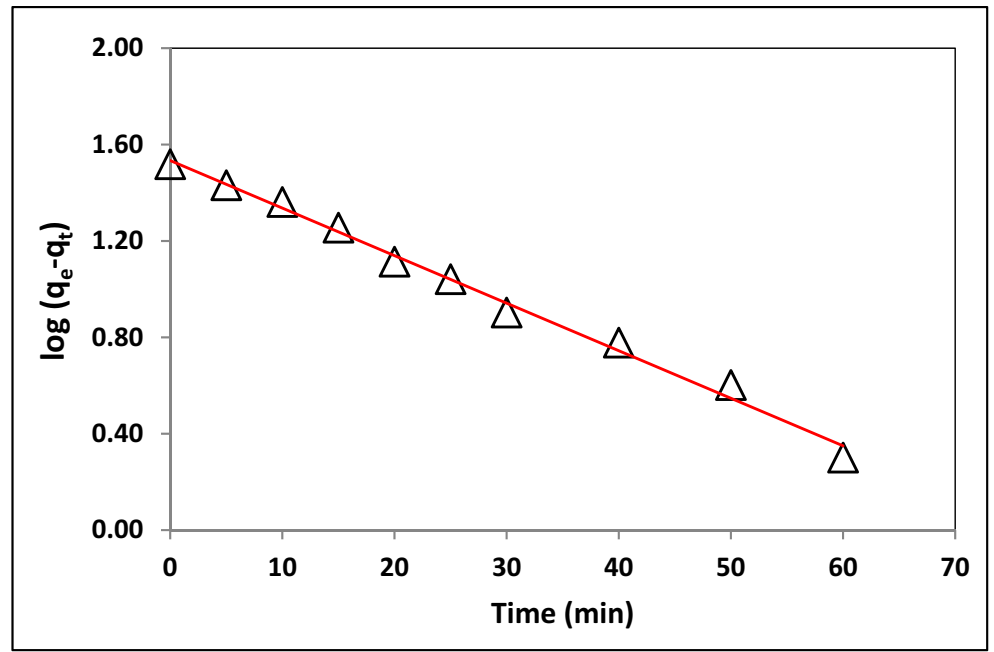

a)

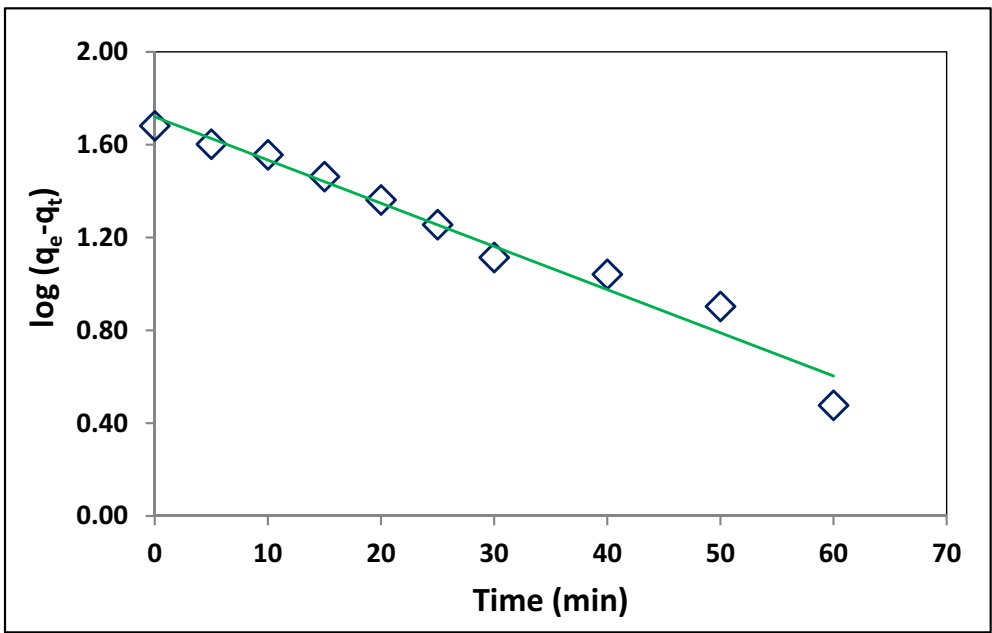

b)

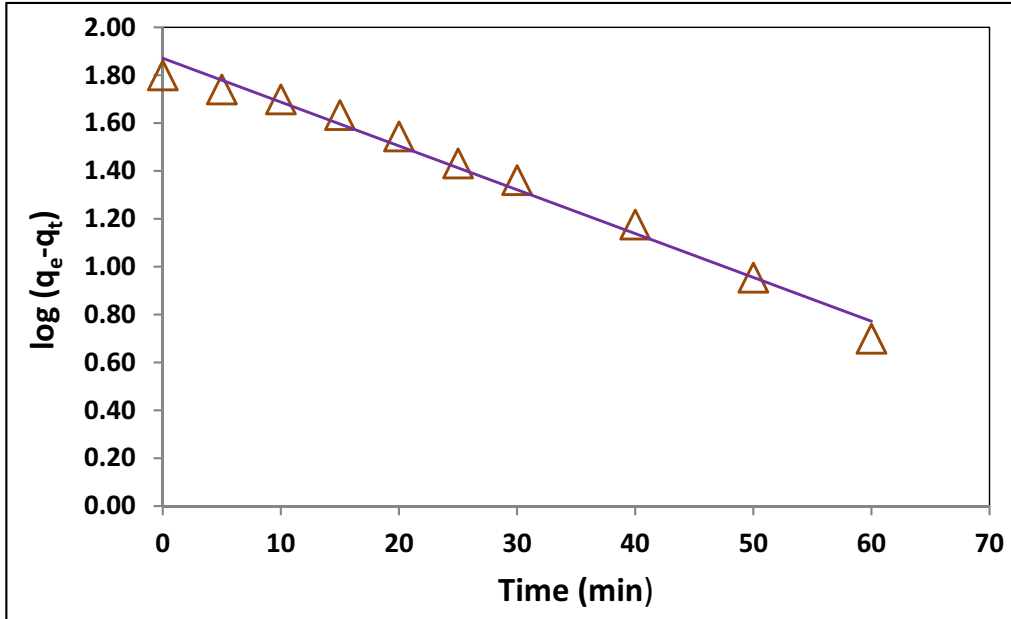

c) 
Fig. 7 Kinetics data fitted to pseudo-second order with initial MG concentration (a) $50 \mu \mathrm{g}$ $\mathrm{mL}^{-1}$, (b) $100 \mu \mathrm{g} \mathrm{mL}^{-1}$, and (c) $200 \mu \mathrm{g} \mathrm{mL}^{-1}$

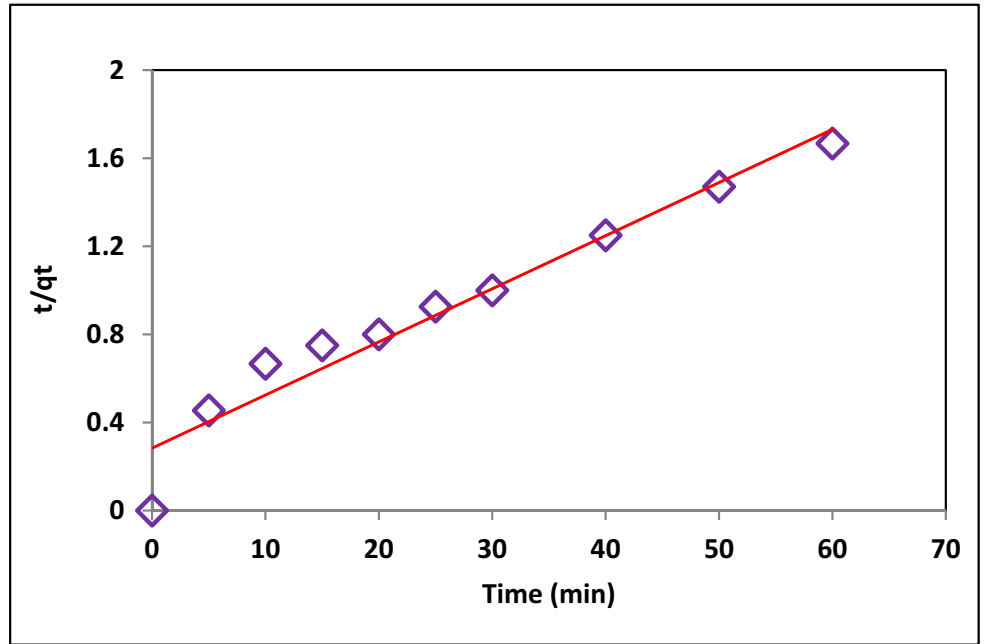

a)

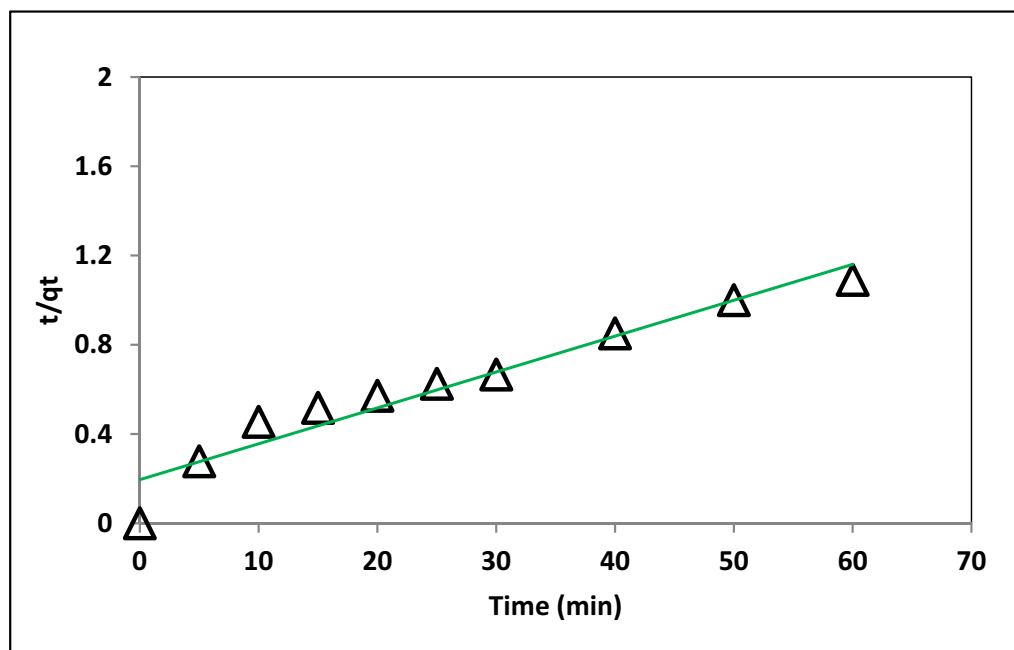

b)

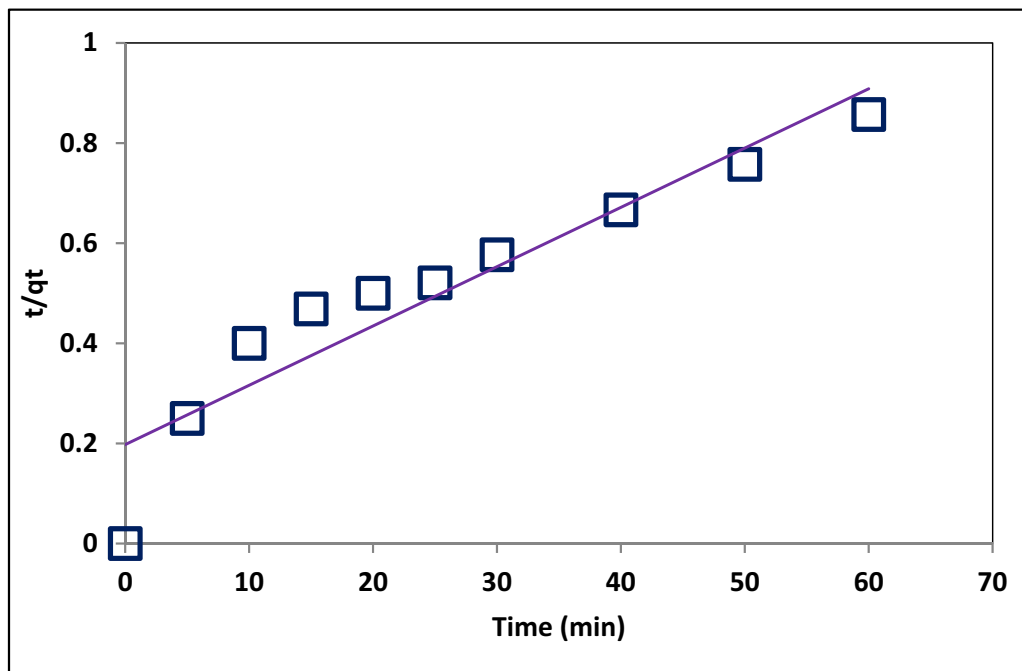

c) 
Table 2 Parameters for adsorption kinetic models

\begin{tabular}{llllllll}
\hline $\begin{array}{l}\text { Initial dye concentra- } \\
\text { tion }\left[\mathrm{mg} \mathrm{L}^{-1}\right]\end{array}$ & \multicolumn{2}{l}{ Pseudo-first-order } & & \multicolumn{3}{l}{ Pseudo-second-order } \\
\cline { 2 - 3 } & $q_{e}\left(\mathrm{mg} \mathrm{g}^{-1}\right)$ & $K_{l}\left(\mathrm{~min}^{-1}\right)$ & $R^{2}$ & & $q_{e}\left(\mathrm{mg} \mathrm{g}^{-1}\right)$ & $K_{l}\left(\mathrm{~min}^{-1}\right)$ & $R^{2}$ \\
\hline 50 & 4.63 & 0.045 & 0.99 & 41.49 & 146.46 & 0.94 \\
100 & 5.58 & 0.042 & 0.97 & 62.11 & 318.03 & 0.93 \\
200 & 6.49 & 0.042 & 0.98 & 84.75 & 428.65 & 0.90 \\
\hline
\end{tabular}

dyestuff manufacturing industry: a review of emerging techniques with reference to biological treatment. Crit Rev Environ Sci Technol 35(3):219-238

9. Khorsandi H, Mohammadi A, Kariminejad F, Haghighi M, Karimzadeh S, Khorsandi J, Aghapour AA (2016) Optimizing linear alkyl benzene sulfonate removal using Fenton oxidation process in Taguchi Method. J Water Chem Technol 38(5):266-272

10. Ibadullaev FY, Melikov NF (2008) Electroseparation of SAS from wastewaters. J Water Chem Technol 30(1):46-50

11. Goncharuk VV, Balakina MN, Kucheruk DD (2010) Electrocoagulation purification of leachate waters of dumping grounds for solid household wastes. J Water Chem Technol 32(3):161-166

12. Dulneva TY, Kucheruk DD, Shvydenko VZ, Titoruk GN, Goncharuk VV (2014) Water treatment of brilliant green using the modified ceramic microfiltration membranes. J Water Chem Technol 36(6):284-287

13. Zahrim AY, Tizaoui C, Hilal N (2011) Coagulation with polymers for nanofiltration pre-treatment of highly concentrated dyes: a review. Desalination 266(1-3):1-16

14. Tan KB, Vakili M, Horri BA, Poh PE, Abdullah AZ, Salamatinia B (2015) Adsorption of dyes by nanomaterials: recent developments and adsorption mechanisms. Sep Purif Technol 150:229-242

15. Fatima B, Siddiqui SI, Nirala RK, Vikrant K, Kim KH, Ahmad R, Chaudhry SA (2021) Facile green synthesis of ${\mathrm{ZnO}-\mathrm{CdWO}_{4}}$ nanoparticles and their potential as adsorbents to remove organic dye. Environ Pollut 271:116401

16. Abdulla NK, Siddiqui SI, Fatima B, Sultana R, Tara N, Hashmi AA, Ahmad R, Mohsin M, Nirala RK, Linh NT, Bach QV (2021) Silver based hybrid nanocomposite: a novel antibacterial material for water cleansing. J Clean Prod 284:124746

17. Siddiqui SI, Chaudhry SA (2019) Nanohybrid composite $\mathrm{Fe}_{2} \mathrm{O}_{3}-\mathrm{ZrO}_{2} / \mathrm{BC}$ for inhibiting the growth of bacteria and

Table 3 Effect of temperature and initial dye concentration on thermodynamic parameters

\begin{tabular}{lllll}
\hline $\begin{array}{l}\text { Initial dye } \\
\text { concentration }\end{array}$ & Temp & $\Delta G^{\circ}$ & $\Delta S^{\circ}$ & $\Delta H^{\circ}$ \\
\hline$\left[\mathrm{mg} \mathrm{L}^{-1}\right]$ & {$[\mathrm{K}]$} & {$\left[\mathrm{kJ} \mathrm{mol}^{-1}\right]$} & {$\left[\mathrm{J} \mathrm{mol}^{-1} \mathrm{~K}^{-1}\right]$} & {$\left[\mathrm{kJ} \mathrm{mol}^{-1}\right]$} \\
50 & 303 & -2.77 & 23.27 & 4.28 \\
& 313 & -3.01 & & \\
& 323 & -2.23 & & \\
100 & 303 & -4.87 & 55.83 & 12.04 \\
& 313 & -5.46 & & \\
& 323 & -5.98 & & \\
200 & 303 & -6.94 & 90.31 & \\
& 313 & -7.82 & & \\
& 323 & -8.74 & & \\
\hline
\end{tabular}

adsorptive removal of arsenic and dyes from water. J Clean Prod 223:849-868

18. Siddiqui SI, Chaudhry SA (2018) Nigella sativa plant based nanocomposite-MnFe2O4/BC: an antibacterial material for water purification. J Clean Prod 200:996-1008

19. Siddiqui SI, Manzoor O, Mohsin M, Chaudhry SA (2019) Nigella sativa seed based nanocomposite- $\mathrm{MnO}_{2} / \mathrm{BC}$ : an antibacterial material for photocatalytic degradation, and adsorptive removal of Methylene blue from water. Environ Res 171:328-340

20. Siddiqui SI, Zohra F, Chaudhry SA (2019) Nigella sativa seed based nanohybrid composite- $\mathrm{Fe}_{2} \mathrm{O}_{3}-\mathrm{SnO}_{2} / \mathrm{BC}$ : a novel material for enhanced adsorptive removal of methylene blue from water. Environ Res 178:108667

21. Siddiqui SI, Rathi G, Chaudhry SA (2018) Acid washed black cumin seed powder preparation for adsorption of methylene blue dye from aqueous solution: thermodynamic, kinetic and isotherm studies. J Mol Liq 264:275-284

22. Korzh EA, Klymenko NA, Smolin SK, Reshetnyak LR (2016) Biosorption of procaine on biologically active carbon. J Water Chem Technol 38(5):287-293

23. Dávila-Jiménez MM, Elizalde-González MP, Peláez-Cid AA (2005) Adsorption interaction between natural adsorbents and textile dyes in aqueous solution. Colloids Surf, A 254(1-3):107-114

24. Szyguła A, Guibal E, Ruiz M, Sastre AM (2008) The removal of sulphonated azo-dyes by coagulation with chitosan. Colloids Surf, A 330(2-3):219-226

25. Pai S, Kini MS, Selvaraj R (2021) A review on adsorptive removal of dyes from wastewater by hydroxyapatite nanocomposites. Environ Sci Pollut Res 28(10):11835-11849

26. Pai S, Kini SM, Selvaraj R, Pugazhendhi A (2020) A review on the synthesis of hydroxyapatite, its composites and adsorptive removal of pollutants from wastewater. J Water Process Eng 38:101574

27. Pai S, Kini SM, Narasimhan MK, Pugazhendhi A, Selvaraj R (2021) Structural characterization and adsorptive ability of green synthesized $\mathrm{Fe}_{3} \mathrm{O}_{4}$ nanoparticles to remove Acid blue 113 dye. Surf Interface 23:100947

28. Taqui SN, Yahya R, Hassan A, Nayak N, Syed AA (2019) A novel sustainable design to develop polypropylene and unsaturated polyester resin polymer composites from waste of major polluting industries and investigation on their physicomechanical and wear properties. Polym Compos 40(3):1142-1157

29. Yakuth SA, Taqui SN, Syed UT, Syed AA (2019) Nutraceutical industrial chillies stalk waste as a new adsorbent for the removal of Acid Violet 49 from water and textile industrial effluent: adsorption isotherms and kinetic models. Desalin Water Treat 155:94-112

30. Papegowda PK, Syed AA (2017) Isotherm, kinetic and thermodynamic studies on the removal of methylene blue dye from aqueous solution using Saw Palmetto spent. International Journal of Environmental Research 11(1):91-98

31. Taqui SN, Yahya R, Hassan A, Nayak N, Syed AA (2019) Adsorption of Acid Blue 113 from aqueous solution onto 
nutraceutical industrial coriander seed spent: Isotherm, kinetics, thermodynamics and modeling studies. Desalin Water Treat 153:321-337. https://doi.org/10.5004/dwt.2019.23913

32. Vargas AM, Cazetta AL, Kunita MH, Silva TL, Almeida VC (2011) Adsorption of methylene blue on activated carbon produced from flamboyant pods (Delonixregia): study of adsorption isotherms and kinetic models. Chem Eng J 168(2):722-730

33. Childress AE, Elimelech M (1996) Effect of solution chemistry on the surface charge of polymeric reverse osmosis and nanofiltration membranes. J Membr Sci 119(2):253-268

34. Taqui SN, Yahya R, Hassan A, Nayak N, Syed AA (2019) Valorization of nutraceutical industrial coriander seed spent by the process of sustainable adsorption system of Acid Black 52 from aqueous solution. International Journal of Environmental Research 13(4):639-659

35. Sulthana R, Taqui SN, Zameer F, Syed UT, Syed AA (2018) Adsorption of ethidium bromide from aqueous solution onto nutraceutical industrial fennel seed spent: Kinetics and thermodynamics modeling studies. Int J Phytorem 20(11):1075-1086

36. Taqui SN, Yahya R, Hassan A, Nayak N, Syed AA (2017) Development of sustainable dye adsorption system using nutraceutical industrial fennel seed spent-studies using Congo red dye. Int J Phytorem 19(7):686-694

37. Fu J, Chen Z, Wang M, Liu S, Zhang J, Zhang J, Han R, Xu Q (2015) Adsorption of methylene blue by a high-efficiency adsorbent (polydopamine microspheres): kinetics, isotherm, thermodynamics and mechanism analysis. Chem Eng J 259:53-61

38. Langmuir I (1916) The constitution and fundamental properties of solids and liquids. Part I. Solids. J Am Chem Soc 38(11):2221-2295
39. Freundlich HMF (1906) Over the adsorption in solution. J Phys Chem 57(385471):1100-1107

40. Lagergren SK (1898) About the theory of so-called adsorption of soluble substances. Kungliga Svenska VetenskapsakademiensHandlingar 24:1-39

41. Ho YS, McKay G (1998) Sorption of dye from aqueous solution by peat. Chem Eng J 70(2):115-124

42. Al-Ghouti MA, Da'ana DA (2020) Guidelines for the use and interpretation of adsorption isotherm models: a review. J Hazard Mater 393:122383

43. Tran HN, You SJ, Hosseini-Bandegharaei A, Chao HP (2017) Mistakes and inconsistencies regarding adsorption of contaminants from aqueous solutions: a critical review. Water Res 120:88-116

44. Lima EC, Hosseini-Bandegharaei A, Moreno-Piraján JC, Anastopoulos I (2019) A critical review of the estimation of the thermodynamic parameters on adsorption equilibria. Wrong use of equilibrium constant in the Van't Hoof equation for calculation of thermodynamic parameters of adsorption, Journal of Molecular Liquids 273:425-434

Publisher's note Springer Nature remains neutral with regard to jurisdictional claims in published maps and institutional affiliations. 